\title{
Application features of MOSFET Spice models in design of radio-electronic equipment
}

\author{
Anton SIDARAS, Elena NOSKOVA and Denis KAPULIN \\ Institute of Space and Information Technologies \\ Siberian Federal University \\ Krasnoyarsk,Russian Federation \\ ASidaras@sfu-kras.ru, ENoskova@sfu-kras.ru, DKapulin@sfu-kras.ru
}

\begin{abstract}
Using the modern elements in a radio-electronic equipment requires close attention to processes as in branch of design and production of electronic components to use the last development in the field simulation of components and in the field computer-aided design of an equipment on the basis of radio-electronic components for the purpose of support adequacy, accuracy and convergence.
\end{abstract}

Possibilities of a solution simulation adequacies of a radioelectronic equipment on the basis of Spice models of electronic components as analysis result and applications of calculation equations of global model parameters are shown.

On the example of use the MOSFET models of different generations the inadequacy reasons of simulation results the transfer characteristic for the matched inverter are shown. Ways for fixing inadequacy calculations through establishment of models parameter values other than values by default are offered. Values Spice directive OPTIONS for support of accuracy and stability in simulation on the basis of the used MOSFET models of different generations are offered.

Index Terms - electronic components, MOSFET Spice model, matched inverter, transfer characteristic, adequacy, convergence, accuracy.

\section{INTRODUCTION}

The use of modern electronic components in the design of electronic equipment requires the application of models and design methods which will ensure the adequacy, accuracy and computational efficiency of computer-aided design. Most of the modern simulation systems with supporting of functional design of electronic equipment are the product of SPICE format evolution, which has become the global standard for circuit simulation. Manufacturers of the radio-electronic components often provides linearized mathematical models of own elements. But it does not provide a complete picture of all the features and characteristics of elements using SPICE models. Such manufacturers refuse to take responsibility for the simulation results using these models.

The calculation of the numerical values of the model parameters model and identification of adequacy areas is implemented in manufacturer's CAD systems. However, the designer have to solve the task of identifying the models parameters of electronic components to ensure the required adequacy of simulation of electronic devices in general. Methodical maintenance of identification process are usually designed directly by the designer. But the result of the identification of the model parameters and the quality of the model depends primarily on the skill of the designer.

Models of radio-electronic components which is used in designing of radio-electronic devices were obtained by theoretical and semi-empirical way, which are formed using the methods of functional-logical, circuitry and physical simulation technology. At the present stage possibilities of the simulation of radio-electronic devices are constantly lagging behind the pace of development of the semiconductor industry techniques. [1]. This is caused by the need to satisfy the conflicting demands on efficiency and adequacy of models as objects of design. Also this is due to the need to combine computational efficiency requirements for calculation methods of component's functional characteristics and stability, convergence and accuracy of the analysis.

The speed of modern simulation systems leads to the use of simplified models of electronic components and, in particular, MOSFET models. At the same time ensuring the adequacy of the simplified models is the most urgent task in the design of electronic devices. With increase of the accuracy of the models, the problem of ensuring the accuracy and convergence of calculating methods of electronic device becomes difficult to solve in general.

Problems, which arise in the use of Spice MOSFET models of the first and the third generations, will be demonstrated. As an example we will consider the parameter calculation of the CMOS inverter with symmetric transfer characteristic. As a model of the first generation "Level 1" will be used and as a model of the third generation we will use "Level 44". [1]: "Level 1" model was the first and the simplest model of MOSFET with long length of the channel. "Level 1" model takes into account only the principle of action of MOSFET. The main difference of "Level 44" model is taking into consideration such physical effects as the dependence of the main parameters of geometry, effects of inhomogeneous doping and others. The remainder of this paper is organized as follows. There are examples in section 2 and 3, which 
represents simulation problems. There is some conclusion in section 4.

\section{EXAMPLE №1.IGNORING THE VALUE OF THE CHARGE} CARRIERS MOBILITY.

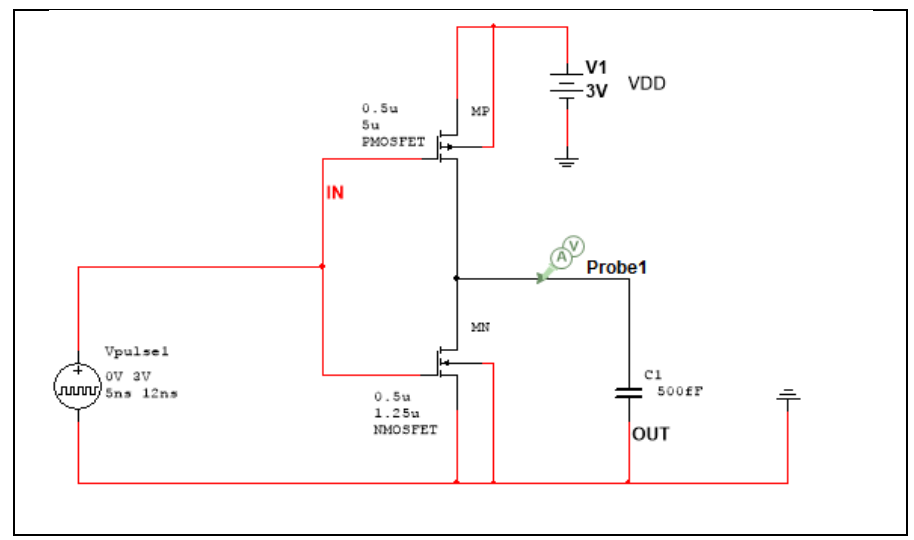

Figure 1 - Matched inverter circuit

This inverter consists of a complementary MOSFET pair. This inverter has symmetric transfer characteristic [3]. It means the channel resistance of open-ended transistors are same and determines by the following formula [3]:

$$
R=\frac{1}{b\left(U_{s d}-U_{0}\right)}
$$

where $U_{0}$ is initial voltage on inverter's input.

To satisfy the equality of resistance, it is necessary to comply with the equality of the coefficients $b$ for the two MOSFETs, that is [3]:

$$
b=b_{n}=b_{p}=\mu_{n} \cdot C_{0} \cdot \frac{W_{n}}{L_{n}}=\mu_{p} \cdot C_{0} \cdot \frac{W_{p}}{L_{p}}
$$

$\mu_{p}, \mu_{n}$-are the mobility factor of the carriers. For the P-type MOSFET the charge carriers are holes. For the N-type MOSFET the charge carriers are electrons. It is known that the mobility of holes is less than the mobility of electrons in the 24 times $[3,5]$, therefore, $\mu_{p}<\mu_{n}$ and $(2-4) \cdot \mu_{p}=\mu_{n}$.

In the production of MOSFET the channel length $\mathrm{L}$ make the same for both types of MOSFETs [3]. For matched devices $C_{0}$ is the same for devices of both types [3]. Therefore, the following relation is:

$$
\frac{W_{p}}{W_{n}}=\frac{\mu_{n}}{\mu_{p}}
$$

Hence we have $W_{n}=(2-4) \cdot W_{p}$. But ratio, based on simulation results, $W_{n}=4 W_{p}$ is recommended to use. However, by default, the built in template model of MOSFET has the same mobility factor of the electrons and holes for both types of transistors [4], that is $\mu_{p}=\mu_{n}$. To avoid the wrong results of model simulation transconductance parameter should be modified. By default, $\mathrm{KP}=2 \cdot 10^{-5} \frac{A}{V^{2}}[4,5]$. By that effect simulation goes wrong and instead of normal transfer characteristic (figure 2) there transfer characteristic has wrong form (figure 3).

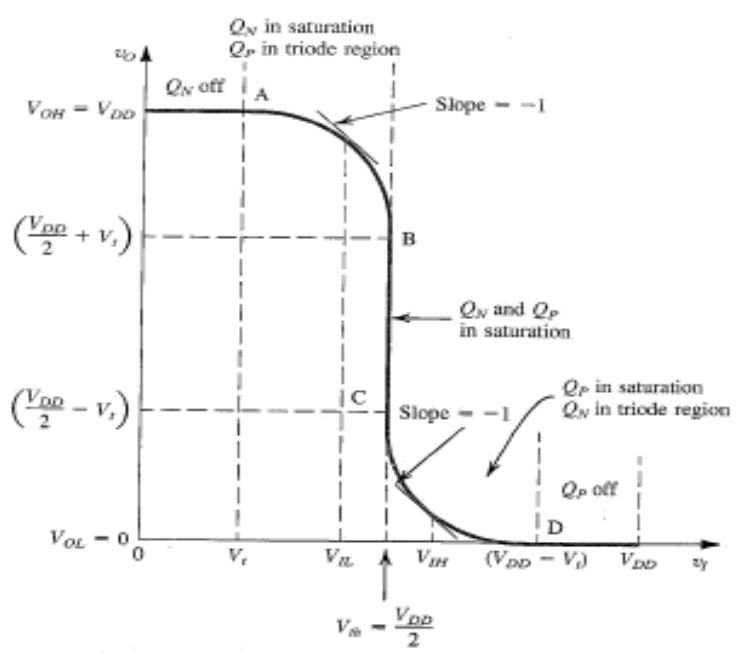

Figure 2 - Normal transfer characteristic [3]

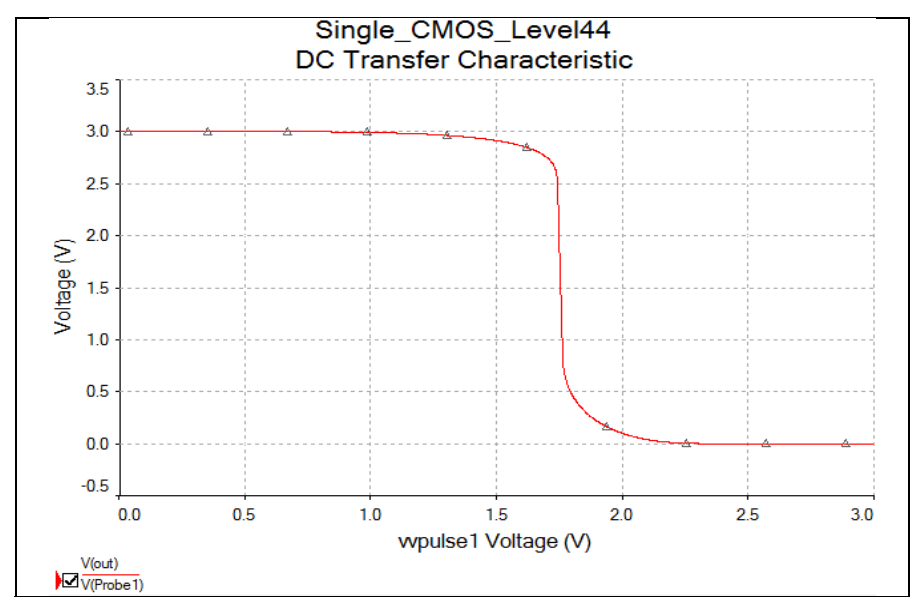

Figure 3 - Wrong transfer characteristic

It is recommended to take the ratio $4 \mu_{p}=\mu_{n}$ to fix the result of simulation. As a result, we obtain the normal transfer characteristic (figure 4).

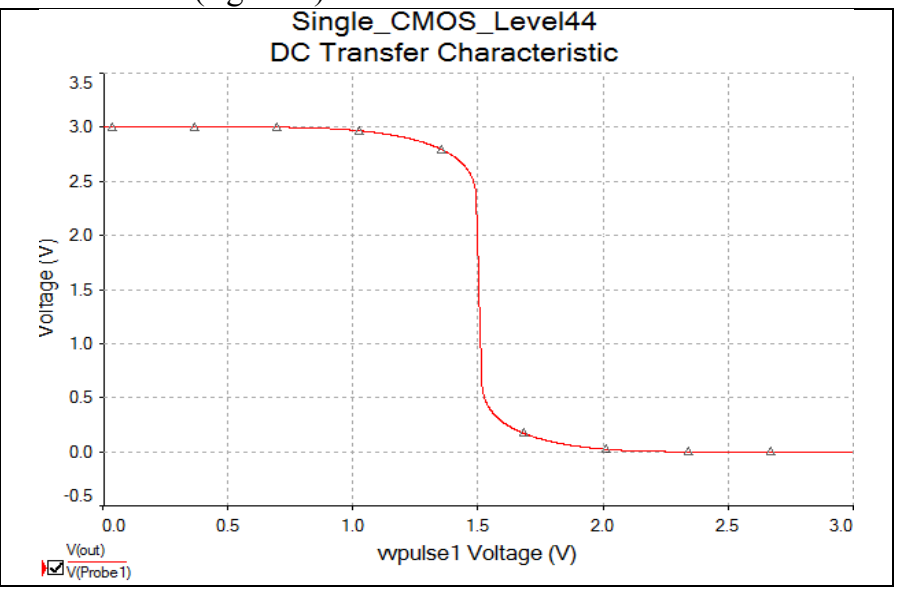

Figure 4 - Fixed transfer characteristic 


\section{EXAMPLE № 2.IGNORING THE MODEL ACCURACY.}

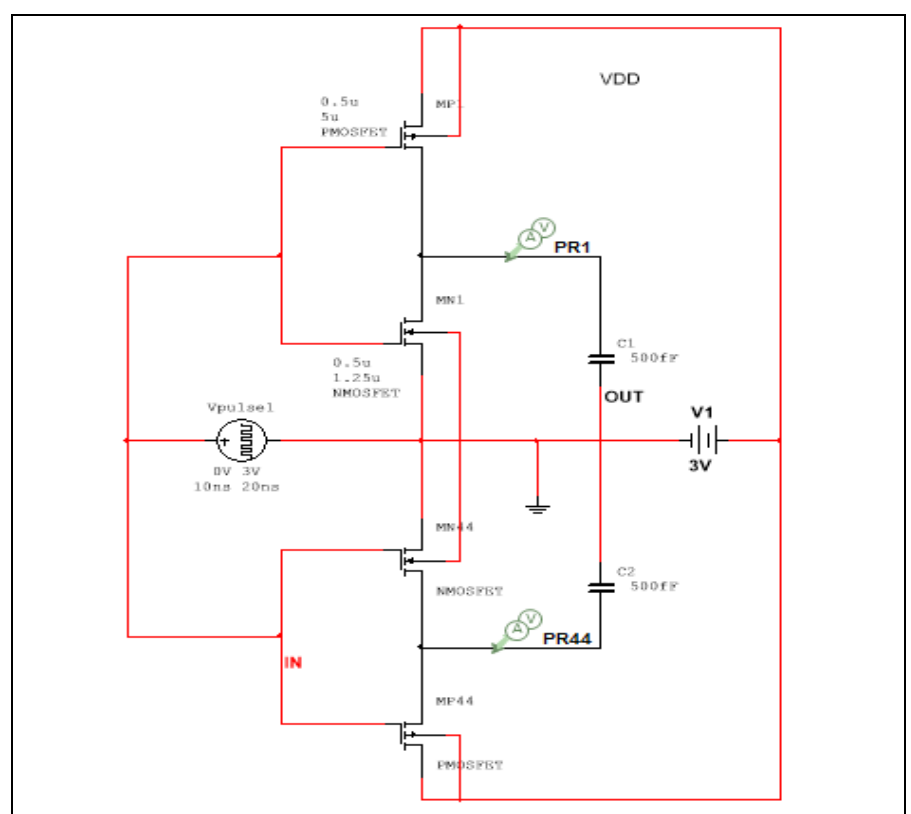

Figure 5 - Matched inverters circuit [3]:

The inverter's threshold voltage determines by this ratio

$$
V_{t h}=\frac{r\left(V_{d d}-\left|V_{t p}\right|\right)+V_{t n}}{1+r} ; r=\sqrt{\frac{k_{p}^{\prime}(W / L) p}{k_{n}^{\prime}(W / L)_{n}}}
$$

For matched inverter:

$$
r=\sqrt{1 \frac{\mathrm{A}}{V^{2}} \cdot 4 / 4 \frac{\mathrm{A}}{V^{2}} \cdot 1}=1 ;(4)\left|V_{t p}\right|=V_{t n}
$$

In this way:

$$
V_{t h}=V_{d d} / 2
$$

As a contrasting example, MOSFETs MP1 and MN1 have "Level 1" models, and MOSFETs MP44 and MN44 have "Level 44" models. Global parameters of "Level 1" and "Level 44" models are the same [4]. We construct a transfer characteristic of both inverters and preliminary assess the simulation results.

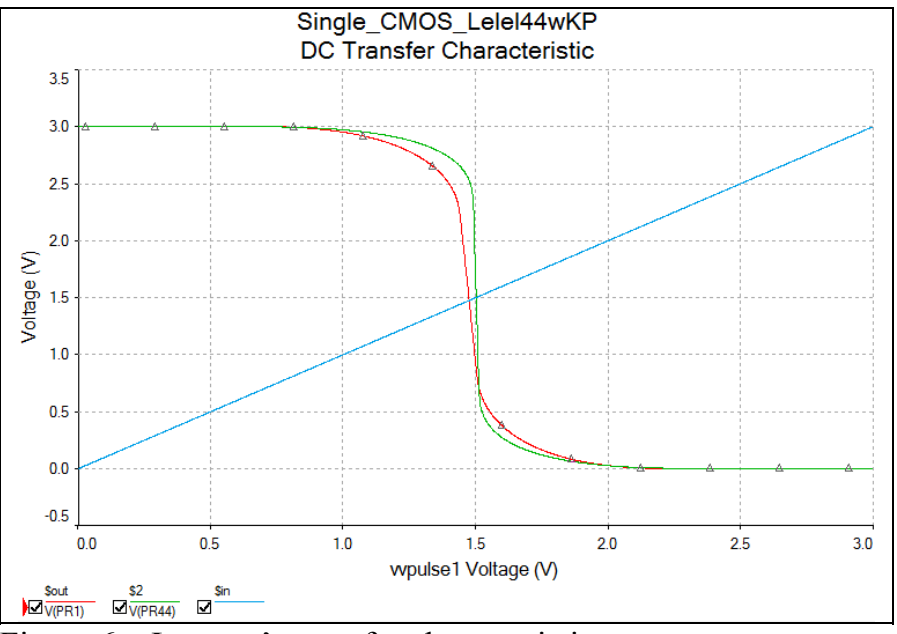

Figure 6 - Inverter's transfer characteristics

Let use an error vector modulus [2]:

$$
\gamma=\sqrt{\left(\frac{\Delta x}{x}\right)^{2}+\left(\frac{\Delta y}{y}\right)^{2}}
$$

It is obvious, that "Level 1" model shows the results worse than "Level 44" model. A simulation result represents $\frac{V_{d d}}{2}>$ $V_{t h}$ in "Level 1" model and $\frac{V_{d d}}{2}=V_{t h}$ in "Level 44" model.

\section{TABLE I}

Errors of "Level 1" model in comparison with the "Level 44" model

\begin{tabular}{|l|c|c|c|}
\hline \multicolumn{1}{|c|}{ X point [3] } & Y point & Differences & Error \\
\hline \hline$V_{I L}$ & $2.860 \mathrm{~V}$ & $\Delta x=0.1016 \mathrm{~V}$ & 0.086 or \\
$=0.425 \cdot V_{d d}$ & & $\Delta y=0.0967 \mathrm{~V}$ & $8.6 \%$ \\
$=1.275 \mathrm{~V}$ & & & \\
\hline$V_{t h}=1.5 \mathrm{~V}$ & $1.5 \mathrm{~V}$ & $\Delta x=0.02 \mathrm{~V} \Delta y=$ & 0.24 or \\
& & $0.37 \mathrm{~V}$ & $24 \%$ \\
\hline$V_{I H}$ & $132 \mathrm{mV}$ & $\Delta x=0.07 \mathrm{~V} \Delta y=$ & 0.48 or \\
$=V d d / 2-V_{I L}$ & & $0.064 \mathrm{~V}$ & $48 \%$ \\
$=1.725 \mathrm{~V}$ & & & \\
\hline
\end{tabular}

"Level 1" model produces the best convergence parameters, less computation time, but its accuracy suffers. There are features in models of other levels, which also represent differences between real and simulated transfer characteristic. [6] This example shows that MOSFET models of last generation are solution to all problems. It is necessary to substantiate the choice of MOSFET model theoretically and practically.

It should be noted, that at sufficiently high simulation time convergence problems arise in the high-end models, in particular, "Level 44" model. For example, it is impossible to simulate circuit indefinitely, because the decision of system of equations goes out of the convergence. This effect can be avoided by parameters tuning of SPICE's format .OPTIONS directive. These parameters are represented in Table II. 
TABLE II

Parameters list to fix convergence problem

\begin{tabular}{|c|c|c|c|}
\hline Code & $\begin{array}{l}\text { Option } \\
\text { name }\end{array}$ & $\begin{array}{c}\text { Descripti } \\
\text { on [7] }\end{array}$ & Recommendation [7] \\
\hline ABSTOL & $\begin{array}{l}\text { Absolut } \\
\text { e error } \\
\text { toleran } \\
\text { ce }\end{array}$ & $\begin{array}{l}\text { Sets the } \\
\text { absolute } \\
\text { error } \\
\text { tolerance } \\
\text {. Default } \\
\text { is } \\
\text { suitable } \\
\text { for most } \\
\text { bipolar } \\
\text { transistor } \\
\text { VLSI } \\
\text { circuits. }\end{array}$ & $\begin{array}{l}\text { If you are simulating } \\
\text { power circuits and } \\
\text { experiencing } \\
\text { convergence problems } \\
\text { or slow-run times, } \\
\text { increase this value; very } \\
\text { tight current tolerances } \\
\text { are generally not } \\
\text { required for these types } \\
\text { of circuits. Values as } \\
\text { high as } 10^{-6} \text { A range are } \\
\text { often acceptable. }\end{array}$ \\
\hline VNTOL & $\begin{array}{l}\text { Voltage } \\
\text { error } \\
\text { toleran } \\
\text { ce }\end{array}$ & $\begin{array}{l}\text { Sets the } \\
\text { absolute } \\
\text { voltage } \\
\text { error } \\
\text { tolerance } \\
\text { of the } \\
\text { program. }\end{array}$ & $\begin{array}{l}\text { If you are simulating } \\
\text { power circuits and } \\
\text { experiencing } \\
\text { convergence problems } \\
\text { or slow-run times, } \\
\text { increase this value; very } \\
\text { tight voltage tolerances } \\
\text { are generally not } \\
\text { required for these types } \\
\text { of circuits. Values as } \\
\text { high as } 10^{-3} \text { V range are } \\
\text { often acceptable. }\end{array}$ \\
\hline RELTOL & $\begin{array}{l}\text { Relativ } \\
\text { e error } \\
\text { toleran } \\
\text { ce }\end{array}$ & $\begin{array}{l}\text { The } \\
\text { value can } \\
\text { significa } \\
\text { ntly } \\
\text { affect the } \\
\text { converge } \\
\text { nce of } \\
\text { the } \\
\text { solution } \\
\text { and the } \\
\text { simulatio } \\
\text { n speed. }\end{array}$ & $\begin{array}{l}\text { If experiencing non- } \\
\text { convergence, loosening } \\
\text { the relative tolerance } \\
\text { often helps. It is } \\
\text { generally not advisable } \\
\text { to increase this value } \\
\text { above } 0.01 .\end{array}$ \\
\hline GMIN & $\begin{array}{l}\text { Minim } \\
\text { um } \\
\text { conduct } \\
\text { ance }\end{array}$ & $\begin{array}{l}\text { Sets the } \\
\text { minimu } \\
\text { m } \\
\text { conducta } \\
\text { nce used } \\
\text { across } \\
\text { junctions } \\
\text { in } \\
\text { semicond } \\
\text { uctor } \\
\text { devices. }\end{array}$ & $\begin{array}{l}\text { Increasing this may } \\
\text { positively improve the } \\
\text { convergence of the } \\
\text { solution, however, it } \\
\text { will also negatively } \\
\text { affect simulation } \\
\text { accuracy. }\end{array}$ \\
\hline PIVREL & $\begin{array}{l}\text { Minim } \\
\text { um } \\
\text { accepta } \\
\text { ble } \\
\text { ratio of } \\
\text { pivot }\end{array}$ & $\begin{array}{l}\text { Resets } \\
\text { the } \\
\text { relative } \\
\text { value } \\
\text { between } \\
\text { the }\end{array}$ & $\begin{array}{l}\text { If experiencing non- } \\
\text { convergence, as an } \\
\text { attempt of last resort, } \\
\text { increase this value. } \\
\text { High values (e.g., } 0.9 \text { ) } \\
\text { have been found to help }\end{array}$ \\
\hline
\end{tabular}

\begin{tabular}{|c|c|c|c|}
\hline & & $\begin{array}{l}\text { largest } \\
\text { column } \\
\text { entry in } \\
\text { the } \\
\text { matrix } \\
\text { and an } \\
\text { acceptabl } \\
\text { e pivot } \\
\text { value. }\end{array}$ & convergence. \\
\hline ITL4 & $\begin{array}{l}\text { Upper } \\
\text { transien } \\
\mathrm{t} \\
\text { iteratio } \\
\mathrm{n} \text { limit }\end{array}$ & $\begin{array}{l}\text { Decreasi } \\
\text { ng the } \\
\text { value } \\
\text { increases } \\
\text { the } \\
\text { chance of } \\
\text { non- } \\
\text { converge } \\
\text { nce. }\end{array}$ & $\begin{array}{l}\text { If you receive the error } \\
\text { message "Time step too } \\
\text { small" or "No } \\
\text { convergence in } \\
\text { transient analysis", } \\
\text { increase the ITL4 re-run } \\
\text { the analysis. }\end{array}$ \\
\hline SUPOSC & $\begin{array}{l}\text { Suppre } \\
\text { ss } \\
\text { numeri } \\
\text { cal } \\
\text { oscillati } \\
\text { ons }\end{array}$ & - & $\begin{array}{l}\text { If experiencing non- } \\
\text { convergence in } \\
\text { transient analysis, } \\
\text { disable this option as a } \\
\text { last resort. }\end{array}$ \\
\hline
\end{tabular}

\section{CONCLUSION}

For obtaining authentic results of calculation the transfer characteristic for the matched inverter it is offered:

1. When using MOSFET Spice models of n-type conductivity to set the value of coefficient of mobility of electrons and holes other than value by default. To accept value transconductance parameter equal $\mathrm{KP}=8 \cdot 10^{-5} \frac{\mathrm{A}}{\mathrm{B}^{2}}$.

2. When using the MOSFET models of different generations of transistors, for example, of Level 1 and Level 44 necessary to consider distinction in calculations of global parameters. Threshold voltage $V_{\text {th }}$ for matched inverter with MOSFET model "Level 1" is determined on expression $\frac{V_{d d}}{2}>V_{t h}$ and for model "Level $44 "$ is determined on expression $\frac{\mathrm{V}_{\mathrm{dd}}}{2}=\mathrm{V}_{\mathrm{th}}$. If not to consider it, then deviations in calculations of the transfer characteristic of matched inverter about 24 percent can reach in $\mathrm{X}$ point where $V_{t h}=1.5 \mathrm{~V}$ with other things being equal.

\section{ACKNOWLEDGMENT}

This work was supported by the Ministry of Education and Science of the Russian Federation in the framework of the Federal target program «Research and development on priority directions of development of the scientific-technological complex of Russia for 2014-2020» (agreement № 14.578.21.0116, unique ID project RFMEFI57815X0116). 


\section{REFERENCES}

[1] Denisenko V.V. Kompatniye modeli MOP-transistorov dlya SPICE $v$ micro i nanoelectronicke. (Compact models for MOSFET SPICE in micro- and nanoelectronics) - M: FIZMATHLIT, p.408., 2010.

[2] Denisenko, «Modelirovanie MOP transistorov. methodologicheski aspect», (Modeling of the MOS transistors. methodological aspect), №7 pp.26-29, №8 pp. 56-61, №9, pp.32-39, 2004., in press

[3] Adel S. Sedra, Kenneth C. Smith, «Microelectronic circuits», New York, Oxford, Oxford University Press, 2004
[4] Selecting a MOSFET Model, Star-Hspice Manual, Release 1998.2.

[5] Adel S. Sedra, Kenneth C. Smith, «Microelectronic circuits» Part 1, New York, Oxford, Oxford University Press, 2010

[6] HSPICE® MOSFET Models Manual, Version X-2005.09, September 2005.

[7] National Instruments Corporation "Multisim help", Part Number: 375482A-01, February 2016, [Online] Available: http://zone.ni.com/reference/enXX/help/375482A01/multisim/c ustomanalysisoptions/\#wp265743 